\title{
Otoimmün tiroid hastalıklarında CTLA-4 geninin in silico analizinin değerlendirilmesi
}

\section{Evaluation of the in silico analysis of CTLA-4 gene in autoimmune thyroid diseases}

\author{
๑Duygu Kırkık, @Sevgi Kalkanlı Taş², ๑Eylem Çağıltay ${ }^{3}$, $\oplus$ Nevin Kalkanlı ${ }^{4}$ \\ ${ }^{1}$ Sağlık Bilimleri Üniversitesi, Hamidiye Tıp Fakültesi, Tibbi Biyoloji Anabilim Dalı, İstanbul, Türkiye \\ ${ }^{2}$ Sağlık Bilimleri Üniversitesi, Hamidiye Tip Fakültesi, İmmünoloji Anabilim Dalı, İstanbul, Türkiye \\ ${ }^{3}$ Sultan Abdülhamid Han Eğitim ve Araştırma Hastanesi, Endokrinoloji ve Metabolizma Hastalıkları Anabilim Dalı, İstanbul, Türkiye \\ ${ }^{4}$ Özel DiyarLife Hastanesi, Dermatoloji Anabilim Dalı, Diyarbakır, Türkiye
}

Cite this article as/Bu makaleye atıf için: Kırkık D, Kalkanlı Taş S, Çağıltay E, Kalkanlı N. Otoimmün tiroid hastalıklarında CTLA-4 geninin in silico analizinin değerlendirilmesi. J Med Palliat Care 2020; 1(3): 58-63.

\section{ÖZ}

Giriş: CTLA-4 (sitotoksik T-lenfosit ilişkili antijen 4) geni, immünoglobulin gen süper ailesinin bir üyesidir ve T hücrelerine inhibe edici bir sinyal ileten proteini kodlamaktadır. Son günlerde immün kontrol noktası olan CTLA-4 geni araştırılan genler arasındadır. Bu çalışmada amaç; CTLA-4 geninde oluşan çeşitli polimorfizmlerin, CTLA-4 geni ile benzer genlerin Otoimmün Tiroid Hastalığı (OTH) patogenezine katkıda bulunabileceğini in silico olarak değerlendirmektir.

Gereç ve Yöntem: Çalışmamızda CTLA-4 geni ile benzer genleri bulmak için GeneMania ve STRING veri tabanları, tek nükleotid polimorfizmlerini (SNP’leri) bulmak için Polyphen2, Exome Variant Server ve SIFT veritabanları, mikro RNA'ları tespit etmek için; miRDB ve miRWalk veritabanları kullanıldı.

Bulgular: Çalışmamızdan elde ettiğimiz verilere göre; FYN geninin OTH’nın patogenezine katkıda bulunabileceğini, CTLA-4 geniyle ilişkili (rs201778935, rs138279736, rs369567630 ve rs376038796) şüpheli SNP’lerin olduğunu tespit ettik.

Sonuç: Çalışmamızda 31 miRNA’nın mesajcı RNA’ların protein üretmesini düzenleyici rol üstlendiğinden, terapötik açıdan önemli olduğunu düşünmekteyiz. Biyoinformatik yöntemlerle değerlendirdiğimiz bu çalışma, ilerde laboratuvar ortamında uygulanarak, birçok hastalığın patogenezinin aydınlatılmasına katkıda bulunabileceğini düşünmekteyiz.

Anahtar Kelimeler: CTLA-4, in silico, mikro RNA, tek nükleotid polimorfizmi, biyoinformatik

\footnotetext{
ABSTRACT

Introduction: CTLA-4 (cytotoxic T-lymphocyte associated antigen-4) gene is a member of the immunoglobulin gene superfamily, encoding the protein that transmits an inhibiting signal to T cells. The CTLA- 4 gene is an immune checkpoint among the genes being investigated nowadays. The aim of this study was to find various polymorphisms in the CTLA- 4 gene may contribute to the pathogenesis of autoimmune thyroid disease (AITD) by investigating the genes that are similar to the CTLA-4 gene.

Material and Method: In our study, we used GeneMania and STRING databases to find similar genes with CTLA-4 gene, then we used Polyphen2, Exome Variant Server and SIFT databases to find single nucleotide polymorphisms (SNPs), miRDB and miRWalk databases were used to detect micro RNAs in the CTLA-4 gene. According to our results, we found that the FYN gene may contribute to the pathogenesis of AITD.

Results: We discovered SNPs (rs201778935, rs138279736, rs369567630 and rs376038796) that are associated with the CTLA-4 gene. In our study, we have thought that 31 miRNAs are therapeutically important, they play a regulatory role in the production of proteins by messenger RNAs.

Conclusion: We believe that this study, which we evaluated with bioinformatics methods, can contribute to the explanation of the pathogenesis of many disease by performing lab based experiments in the future.

Keywords: CTLA-4; in silico; miRNA; single nucleotide polymorphism; bioinformatics 


\section{GíRiş}

Sitotoksik $\mathrm{T}$ lenfosit ilişkili antijen 4 (CTLA-4), immünoglobulin gen süper ailesinin bir üyesidir ve $\mathrm{T}$ hücrelerine inhibe edici sinyal ileten, proteini kodlamaktadır (1). Bu protein bir $\mathrm{V}$ domaini, bir transmembran domain ve bir sitoplazmik kuyruk içermektedir. Farklı izoformları kodlayan alternatif transkripsiyonel ek varyantları karakterize edilmiştir. Membrana bağlı izoform, bir disülfür bağ 1 ile birbirine bağlanmış bir homodimer olarak işlev görürken, çözünür izoformu monomer olarak işlev görmektedir (25). CTLA-4; (CD152 olarak da bilinir) immünolojik bir kontrol noktasıdır ve periferik toleransin korunmasinda merkezi ve önemli bir role sahiptir $(6,7)$. CTLA-4, CD28'e homolog olmasina rağmen; CTLA-4 hücre içi kompartmanda bulunur ve sadece istirahat eden $\mathrm{T}$ hücrelerinin yüzeyinde minimal olarak eksprese olmaktadır (8). Her iki reseptör de antijen sunan hücrelerin (APC'lerin) yüzeyinde ifade edilen bir CD80 ve CD86 olmak üzere çift ligand paylaşmaktadır. CD28, daha yüksek afiniteli CD80 dimeri ve daha düşük afiniteli olan CD86 monomeri ile etkileşime girerek T hücresi reseptörü (TCR) sinyalleri ile birlikte T hücre aracılı costimulasyona aracilık eder (9).

Otoimmün hastalıkların çoğunda kalıtım paterni çok karmaşıktır. Major histokompabilite kompleksi (MHC), otoimmün hastalıklara yatkınlıkta temel genetik bileşen olarak gösterilmiştir, ancak diğer genlerin de dahil olması muhtemeldir. Fonksiyonel ve deneysel verilere dayanarak, CTLA-4'ü kodlayan genin, otoimmüniteye duyarlılık kazandırmak için aday bir gen olduğu öne sürülmüştür (10). Bu gendeki mutasyonlar tip 1 diabetes mellitus (11), çölyak hastalığ 1 (12), sistemik lupus eritematozus (13), tiroid ile ilişkili orbitopati ve diğer otoimmün hastalıklar ile ilişkilendirilmiştir. Günümüzde, popülasyonun yaklaşık \%5'i otoimmün tiroid hastalıkları (OTH) ile yaşamını sürdürmektedir. Yapılan çalışmalar hastalığın oluşmasında etkili olan genetik faktörlerin ya da genetik yatkınlığın altını çizmiştir. Son günlerde immünolojik bir kontrol merkezi olan CTLA-4 geni araştırılan genler arasındadır. Biz de bu çalışmada CTLA-4 geniyle ilişkili benzer genleri, bu gende bulunan polimorfizmleri ve miRNA'ları OTH'ların oluşum mekanizmasına katkıda bulunması amacıyla değerlendirdik.

\section{GEREÇ VE YÖNTEM}

Tüm prosedürler etik kurallara ve Helsinki İlkeler Bildirgesi'ne uygun olarak gerçekleştirilmiştir. $\mathrm{Bu}$ çalışmada in silico metotlar kullanılmıştır ve herhangi bir etik kurul onayı gerektirmemektedir.

\section{CTLA-4 Geni Hakkındaki Verilerin Toplanması}

CTLA-4 geni hakkındaki veriler Online Mendelian Inheritance in Man (OMIM) (14) ve National Center for
Biological Information (NCBI) sitelerinden toplanmıştır (15). CTLA-4 geninin SNP bilgileri (protein erişim numarası ve SNP ID) NCBI dbSNP ve SWISS Prot veritabanlarından alınmıştır (16).

\section{CTLA-4 ile Fonksiyonel Olarak Benzer Genlerin Analiz Edilmesi}

Çalışmamızda CTLA-4 geni ile fonksiyonel olarak benzer genlerin analizi GeneMania ve STRING veritabanları yardımıyla gerçekleştirildi $(17,18) . \mathrm{Bu}$ veritabanları aracılığ1 ile fiziksel etkileşimler, ortak ifadeler, ortak lokalizasyon, ortak genetik etkileşimler gösterildi. [Bu verilere https:// genemania. org ve http://www.bork. embl-heidelberg.de/STRING/ adresinden ulaşılabilir.]

\section{CTLA-4 Genindeki Şüpheli SNP’lerin Tespiti}

Exome Variant Server, Ulusal Kalp, Akciğer ve Kan Enstitüsü (NHLBI) tarafından desteklenen bir veri tabanıdır (19). Bu veri tabanının amacı kalp, akciğer ve kan bozukluklarına yeni genler ve mekanizmalar bulmaktır [Bu veritabanına http://evs.gs.washington. edu/EVS/ adresinden ulaşılabilmektedir]. Exome Variant Server Avrupalı Amerikan popülasyonu allel sayıları ve Afrikalı Amerikan popülasyonu allel sayılarının gözlemlenmesine izin vermektedir. Çalışmamızda CTLA4 genindeki şüpheli SNP'ler analiz edildi. Sonuçlarımız SIFT ve Polyphen2 veritabanları ile karşılaştırılarak, değerlendirildi $(20,21)$.

\section{CTLA-4 Genindeki miRNA'ların Bulunması}

miRDB; hedef miRNA tahmini yapmak için kullanılan bir veritabanıdır. miRDB insan, fare, sıçan, köpek ve tavuk gibi beşfarklı türde hedef miRNA tahmini yaparak, fonksiyonel olarak aktif miRNA'ları tanımlamaktadır. Çalışmamızda insanda CTLA-4 genine özgü miRNA tahmini yapıldı ve miRDB veritabanıla bulunan hedef mİRNA'lar, mİRWalk veritabanı yardımıyla karşılaştırılıp, değerlendirildi $(22,23)$. [Bu verilere http://mirdb.org/ ve http://zmf.umm.uni-heidelberg.de/ adresinden ulaşılabilir].

\section{BULGULAR}

CTLA-4 ile fonksiyonel olarak benzer, on farklı gen STRING ve GeneMania veritabanıyla analiz edildi. Bunlar; FOXP3, ITGA4, IL17A, ICOSL, ITGAL, CD86, CD80, FYN, PTPN11 ve LCK'dır (Şekil 1). Daha sonrasinda CTLA-4 geninde bulunan Avrupalı Amerikan ve Afrikalı Amerikan ırklarına ait şüpheli SNP’ler Exome Variant Server, Polyphen2 ve SIFT veritabanlariyla tespit edildi. Avrupalı Amerikan ve Afrikalı Amerikan popülasyonlarına ait 34 mutasyon tespit ettik (Tablo 1). Son olarak; CTLA-4 genindeki miRNA'lar miRDB veritabanıyla bulunarak, mirWalk veritabanıyla valide edildi. CTLA-4 geninde bulunan, önemli olduğunu düşündügümüz 31 miRNA tespit ettik (Tablo 2). 
Tablo 1. Missense (kırmızi), coding synonymous (yeşil), UTR (turuncu), intron (beyaz) NHLBI Exome Sequencing Project’i tanımlayan CTLA-4 geninin SNP'leri

\begin{tabular}{|c|c|c|c|c|c|c|c|}
\hline rs ID & Alleles & All Alleles & All Genotype \# & $\begin{array}{c}\text { Avg. } \\
\text { Sample } \\
\text { Read } \\
\text { Depth }\end{array}$ & GVS Function & $\begin{array}{l}\text { cDNA } \\
\text { Change }\end{array}$ & $\begin{array}{c}\text { PolyPhen2 } \\
\text { (Class:Score) }\end{array}$ \\
\hline rs201778935 & $\mathrm{C}>\mathrm{T}$ & $\mathrm{T}=1 / \mathrm{C}=13005$ & $\mathrm{TT}=0 / \mathrm{TC}=1 / \mathrm{CC}=6502$ & 118 & missense & c. $22 \mathrm{C}>\mathrm{T}$ & $\begin{array}{c}\text { probably- } \\
\text { damaging:1.0 }\end{array}$ \\
\hline rs138279736 & $\mathrm{G}>\mathrm{A}$ & $A=3 / G=13003$ & $\mathrm{AA}=0 / \mathrm{AG}=3 / \mathrm{GG}=6500$ & 123 & missense & c. $23 \mathrm{G}>\mathrm{A}$ & $\begin{array}{c}\text { probably- } \\
\text { damaging:0.996 }\end{array}$ \\
\hline rs146541851 & $A>G$ & $\mathrm{G}=1 / \mathrm{A}=13005$ & $\mathrm{GG}=0 / \mathrm{GA}=1 / \mathrm{AA}=6502$ & 127 & missense & c. $28 \mathrm{~A}>\mathrm{G}$ & benign: 0.0 \\
\hline rs376591332 & $\mathrm{C}>\mathrm{T}$ & $\mathrm{T}=1 / \mathrm{C}=13005$ & $\mathrm{TT}=0 / \mathrm{TC}=1 / \mathrm{CC}=6502$ & 135 & $\begin{array}{c}\text { coding- } \\
\text { synonymous }\end{array}$ & c. $42 \mathrm{C}>\mathrm{T}$ & unknown \\
\hline rs231775 & $A>G$ & $\mathrm{G}=4805 / \mathrm{A}=8201$ & $\mathrm{GG}=881 / \mathrm{GA}=3043 / \mathrm{AA}=2579$ & 140 & missense & c. $49 \mathrm{~A}>\mathrm{G}$ & benign:0.015 \\
\hline rs16840275 & $\mathrm{G}>\mathrm{C}$ & $\mathrm{C}=122 / \mathrm{G}=12884$ & $\mathrm{CC}=0 / \mathrm{CG}=122 / \mathrm{GG}=6381$ & 141 & $\begin{array}{c}\text { coding- } \\
\text { synonymous }\end{array}$ & c. $75 \mathrm{G}>\mathrm{C}$ & unknown \\
\hline rs145950656 & $\mathrm{C}>\mathrm{T}$ & $\mathrm{T}=2 / \mathrm{C}=13004$ & $\mathrm{TT}=0 / \mathrm{TC}=2 / \mathrm{CC}=6501$ & 136 & $\begin{array}{l}\text { coding- } \\
\text { synonymous }\end{array}$ & c. $87 \mathrm{C}>\mathrm{T}$ & unknown \\
\hline rs369567630 & $\mathrm{C}>\mathrm{T}$ & $\mathrm{T}=1 / \mathrm{C}=13005$ & $\mathrm{TT}=0 / \mathrm{TC}=1 / \mathrm{CC}=6502$ & 133 & missense & c. $94 \mathrm{C}>\mathrm{T}$ & $\begin{array}{c}\text { probably- } \\
\text { damaging:0.999 }\end{array}$ \\
\hline rs372230996 & $\mathrm{G}>\mathrm{T}$ & $\mathrm{T}=1 / \mathrm{G}=13005$ & $\mathrm{TT}=0 / \mathrm{TG}=1 / \mathrm{GG}=6502$ & 79 & intron & c. $109+32 \mathrm{G}>\mathrm{T}$ & unknown \\
\hline rs376571886 & $\mathrm{C}>\mathrm{T}$ & $\mathrm{T}=1 / \mathrm{C}=13003$ & $\mathrm{TT}=0 / \mathrm{TC}=1 / \mathrm{CC}=6501$ & 27 & intron & c. $110-39 \mathrm{C}>\mathrm{T}$ & unknown \\
\hline rs376860736 & $\mathrm{G}>\mathrm{A}$ & $A=2 / G=13004$ & $\mathrm{AA}=0 / \mathrm{AG}=2 / \mathrm{GG}=6501$ & 29 & intron & c. $110-34 \mathrm{G}>\mathrm{A}$ & unknown \\
\hline rs369073139 & $\mathrm{T}>\mathrm{C}$ & $\mathrm{C}=2 / \mathrm{T}=13004$ & $\mathrm{CC}=0 / \mathrm{CT}=2 / \mathrm{TT}=6501$ & 32 & intron & c. $110-28 \mathrm{~T}>\mathrm{C}$ & unknown \\
\hline rs369257616 & $\mathrm{C}>\mathrm{A}$ & $A=1 / C=13005$ & $\mathrm{AA}=0 / \mathrm{AC}=1 / \mathrm{CC}=6502$ & 36 & intron & c. $110-22 \mathrm{C}>\mathrm{A}$ & unknown \\
\hline rs146200342 & $\mathrm{C}>\mathrm{T}$ & $\mathrm{T}=1 / \mathrm{C}=13005$ & $\mathrm{TT}=0 / \mathrm{TC}=1 / \mathrm{CC}=6502$ & 68 & $\begin{array}{c}\text { coding- } \\
\text { synonymous }\end{array}$ & c. $139 \mathrm{C}>\mathrm{T}$ & unknown \\
\hline rs373393185 & $\mathrm{G}>\mathrm{A}$ & $A=1 / G=13005$ & $\mathrm{AA}=0 / \mathrm{AG}=1 / \mathrm{GG}=6502$ & 98 & $\begin{array}{c}\text { coding- } \\
\text { synonymous }\end{array}$ & c. $171 \mathrm{G}>\mathrm{A}$ & unknown \\
\hline rs139154557 & $\mathrm{T}>\mathrm{C}$ & $\mathrm{C}=1 / \mathrm{T}=13005$ & $\mathrm{CC}=0 / \mathrm{CT}=1 / \mathrm{TT}=6502$ & 129 & $\begin{array}{c}\text { coding- } \\
\text { synonymous }\end{array}$ & c. $246 \mathrm{~T}>\mathrm{C}$ & unknown \\
\hline rs376038796 & $\mathrm{C}>\mathrm{T}$ & $\mathrm{T}=1 / \mathrm{C}=13005$ & $\mathrm{TT}=0 / \mathrm{TC}=1 / \mathrm{CC}=6502$ & 136 & missense & c. $257 \mathrm{C}>\mathrm{T}$ & $\begin{array}{c}\text { probably- } \\
\text { damaging:1.0 }\end{array}$ \\
\hline rs370443546 & $A>G$ & $\mathrm{G}=1 / \mathrm{A}=13005$ & $\mathrm{GG}=0 / \mathrm{GA}=1 / \mathrm{AA}=6502$ & 141 & missense & c. $268 \mathrm{~A}>\mathrm{G}$ & benign:0.002 \\
\hline rs144988077 & $\mathrm{G}>\mathrm{A}$ & $A=2 / G=13004$ & $\mathrm{AA}=0 / \mathrm{AG}=2 / \mathrm{GG}=6501$ & 131 & missense & c. $326 \mathrm{G}>\mathrm{A}$ & benign:0.366 \\
\hline rs372929906 & $\mathrm{G}>\mathrm{A}$ & $A=2 / G=13004$ & $\mathrm{AA}=0 / \mathrm{AG}=2 / \mathrm{GG}=6501$ & 115 & $\begin{array}{c}\text { coding- } \\
\text { synonymous }\end{array}$ & c. $372 \mathrm{G}>\mathrm{A}$ & unknown \\
\hline rs147679342 & $\mathrm{G}>\mathrm{A}$ & $A=1 / G=13005$ & $\mathrm{AA}=0 / \mathrm{AG}=1 / \mathrm{GG}=6502$ & 100 & $\begin{array}{l}\text { coding- } \\
\text { synonymous }\end{array}$ & c. $390 \mathrm{G}>\mathrm{A}$ & unknown \\
\hline rs376126248 & $\mathrm{A}>\mathrm{T}$ & $\mathrm{T}=1 / \mathrm{A}=13005$ & $\mathrm{TT}=0 / \mathrm{TA}=1 / \mathrm{AA}=6502$ & 77 & $\begin{array}{c}\text { coding- } \\
\text { synonymous }\end{array}$ & c. $414 \mathrm{~A}>\mathrm{T}$ & unknown \\
\hline rs368427057 & $\mathrm{C}>\mathrm{T}$ & $\mathrm{T}=2 / \mathrm{C}=13004$ & $\mathrm{TT}=0 / \mathrm{TC}=2 / \mathrm{CC}=6501$ & 46 & intron & c. $457+12 \mathrm{C}>\mathrm{T}$ & unknown \\
\hline rs41265959 & $\mathrm{T}>\mathrm{C}$ & $\mathrm{C}=2 / \mathrm{T}=13004$ & $\mathrm{CC}=0 / \mathrm{CT}=2 / \mathrm{TT}=6501$ & 40 & intron & c. $457+24 \mathrm{~T}>\mathrm{C}$ & unknown \\
\hline rs200271600 & $\mathrm{G}>\mathrm{T}$ & $\mathrm{T}=1 / \mathrm{G}=13005$ & $\mathrm{TT}=0 / \mathrm{TG}=1 / \mathrm{GG}=6502$ & 111 & intron & c. $458-24 \mathrm{G}>\mathrm{T}$ & unknown \\
\hline rs200657280 & $\mathrm{G}>\mathrm{A}$ & $A=2 / G=13004$ & $\mathrm{AA}=0 / \mathrm{AG}=2 / \mathrm{GG}=6501$ & 165 & $\begin{array}{c}\text { coding- } \\
\text { synonymous }\end{array}$ & c. $468 \mathrm{G}>\mathrm{A}$ & unknown \\
\hline rs200657280 & $\mathrm{G}>\mathrm{A}$ & $A=2 / G=13004$ & $\mathrm{AA}=0 / \mathrm{AG}=2 / \mathrm{GG}=6501$ & 165 & intron & c. $457+455 \mathrm{G}>\mathrm{A}$ & unknown \\
\hline rs375949600 & $\mathrm{G}>\mathrm{A}$ & $A=2 / G=13004$ & $\mathrm{AA}=0 / \mathrm{AG}=2 / \mathrm{GG}=6501$ & 192 & $\begin{array}{c}\text { coding- } \\
\text { synonymous }\end{array}$ & c. $516 \mathrm{G}>\mathrm{A}$ & unknown \\
\hline rs375949600 & $\mathrm{G}>\mathrm{A}$ & $A=2 / G=13004$ & $\mathrm{AA}=0 / \mathrm{AG}=2 / \mathrm{GG}=6501$ & 192 & intron & c. $457+503 \mathrm{G}>\mathrm{A}$ & unknown \\
\hline rs146571801 & $\mathrm{A}>\mathrm{T}$ & $\mathrm{T}=1 / \mathrm{A}=13005$ & $\mathrm{TT}=0 / \mathrm{TA}=1 / \mathrm{AA}=6502$ & 160 & $\begin{array}{c}\text { coding- } \\
\text { synonymous }\end{array}$ & c. $546 \mathrm{~A}>\mathrm{T}$ & unknown \\
\hline rs146571801 & $\mathrm{A}>\mathrm{T}$ & $\mathrm{T}=1 / \mathrm{A}=13005$ & $\mathrm{TT}=0 / \mathrm{TA}=1 / \mathrm{AA}=6502$ & 160 & intron & c. $457+533 \mathrm{~A}>\mathrm{T}$ & unknown \\
\hline rs369757839 & $\mathrm{G}>\mathrm{A}$ & $A=1 / G=13005$ & $\mathrm{AA}=0 / \mathrm{AG}=1 / \mathrm{GG}=6502$ & 58 & utr-3 & c. ${ }^{*} 12 \mathrm{G}>\mathrm{A}$ & unknown \\
\hline rs373219319 & $\mathrm{A}>\mathrm{G}$ & $\mathrm{G}=2 / \mathrm{A}=13004$ & $\mathrm{GG}=0 / \mathrm{GA}=2 / \mathrm{AA}=6501$ & 50 & utr-3 & c. ${ }^{*} 26 \mathrm{~A}>\mathrm{G}$ & unknown \\
\hline rs34162447 & $A>G$ & $\mathrm{G}=10 / \mathrm{A}=12996$ & $\mathrm{GG}=0 / \mathrm{GA}=10 / \mathrm{AA}=6493$ & 45 & utr-3 & c. $* 34 \mathrm{~A}>\mathrm{G}$ & unknown \\
\hline
\end{tabular}




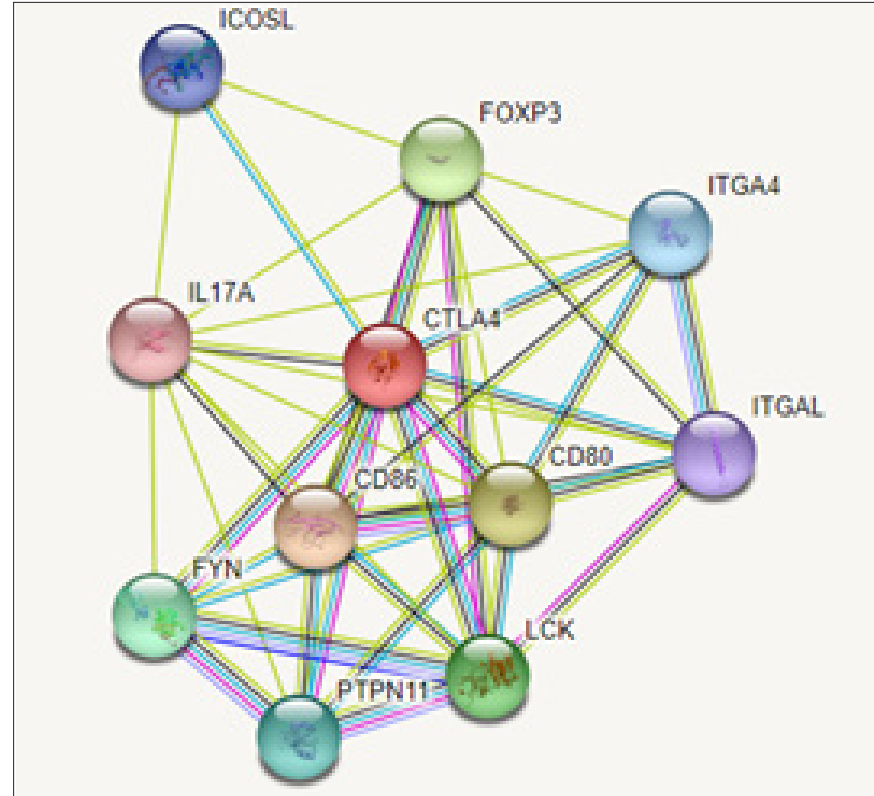

Şekil 1. CTLA-4 ve CTLA-4 ile ilişkili genlerin aralarındaki bağlantının değerlendirilmesi (fiziksel etkileşimler pembe, coexpression lila rengi ile gösterilmiștir.)

\section{Tablo 2. CTLA-4 genindeki miRNA'lar}

\begin{tabular}{|c|c|c|c|}
\hline $\begin{array}{l}\text { Target } \\
\text { Rank }\end{array}$ & $\begin{array}{l}\text { Target } \\
\text { Score }\end{array}$ & miRNA Name & Gene Symbol \\
\hline 1 & 100 & hsa-miR-5011-5p & CTLA-4 \\
\hline 2 & 100 & hsa-miR-190a-3p & CTLA-4 \\
\hline 3 & 95 & hsa-miR-7-1-3p & CTLA-4 \\
\hline 4 & 95 & hsa-miR-7-2-3p & CTLA-4 \\
\hline 5 & 95 & hsa-miR-1250-3p & CTLA-4 \\
\hline 6 & 94 & hsa-miR-4255 & CTLA-4 \\
\hline 7 & 92 & hsa-miR-3177-5p & CTLA-4 \\
\hline 8 & 92 & hsa-miR-4778-3p & CTLA-4 \\
\hline 9 & 91 & hsa-miR-3658 & CTLA-4 \\
\hline 10 & 90 & hsa-miR-6715b-3p & CTLA-4 \\
\hline 11 & 89 & hsa-miR-7162-5p & CTLA-4 \\
\hline 12 & 89 & hsa-miR-516b-3p & CTLA-4 \\
\hline 13 & 89 & hsa-miR-516a-3p & CTLA-4 \\
\hline 14 & 88 & hsa-miR-548p & CTLA-4 \\
\hline 15 & 87 & hsa-miR-496 & CTLA-4 \\
\hline 16 & 86 & hsa-miR-542-3p & CTLA-4 \\
\hline 17 & 85 & hsa-miR-502-5p & CTLA-4 \\
\hline 18 & 83 & hsa-miR-3148 & CTLA-4 \\
\hline 19 & 81 & hsa-miR-4424 & CTLA-4 \\
\hline 20 & 81 & hsa-miR-6868-3p & CTLA-4 \\
\hline 21 & 80 & hsa-miR-6124 & CTLA-4 \\
\hline 22 & 80 & hsa-miR-6715a-3p & CTLA-4 \\
\hline 23 & 80 & hsa-miR-4311 & CTLA-4 \\
\hline 24 & 80 & hsa-miR-7843-3p & CTLA-4 \\
\hline 25 & 79 & hsa-miR-324-5p & CTLA-4 \\
\hline 26 & 78 & hsa-miR-6716-5p & CTLA-4 \\
\hline 27 & 78 & hsa-miR-656-3p & CTLA-4 \\
\hline 28 & 78 & hsa-miR-3121-5p & CTLA-4 \\
\hline 29 & 77 & hsa-miR-6499-3p & CTLA-4 \\
\hline 30 & 76 & hsa-miR-3910 & CTLA-4 \\
\hline 31 & 75 & hsa-miR-6083 & CTLA-4 \\
\hline
\end{tabular}

\section{TARTIŞMA}

CTLA-4; APC'ler üzerindeki CD80 ve CD86 gibi aynı ligandları kullanarak pozitif ve negatif kostimülasyona aracılık eden, $\mathrm{T}$ hücreleri üzerindeki birincil eş reseptörlerdir. CD28'in tetiklenmesiyle, IL-2 üretimi ve $\mathrm{T}$ hücresi proliferasyonu güçlü bir şekilde düzenlenmektedir (24). CTLA-4; CD28 aracilı etkilere engel olmakla kalmaz, aynı zamanda apoptoza karşı direnci arttırarak sinerjiye de neden olabilmektedir (25). CTLA-4 düzenleyici T hücreleri (Tregs) efektör $\mathrm{T}$ hücrelerinin fonksiyonlarını kontrol eder ve böylece periferik toleransı korumada kilit oyuncudur $(26,27)$. Deneyimizin ilk aşamasından elde ettiğimiz verilere göre; CTLA-4 geninin FOXP3, ITGA4, IL17A, ICOSL, ITGAL, CD86, CD80, FYN, PTPN11 ve LCK genleri ile hem fiziksel etkileşim hem de ortak ekspresyonun olduğunu tespit ettik. Tespit ettiğimiz her benzer genin literatürde immün sistemde çok önemli fonksiyonunun olduğu tanımlanmıştır. Örneğin; IL-17A, çeşitli mikrobiyal patojenlere ve doku iltihabına karşı konak savunmasında kritik bir rol oynamaktadır (28). FOXP3'ün fonksiyonu, NFAT ve NF-кB'ın işlevini bastırmaktır. IL-2 ve efektör T-hücresi sitokinleri de dahil olmak üzere birçok genin ekspresyonunun bastırılmasına yardımcı olmaktır (29). Daha önceki çalışmalar; ICOSL, FOXP3, IL17A, CD86, CD80, PTPN11 otoimmün tiroid hastalıklarıyla (OTH) ilişkili olduğu gösterilmiştir (30-33). Şekil 1'de gösterilen CTLA-4 geninin ortak ekspresyon yaptığı genlerden biri de FYN genidir ve henüz bu gen hakkında OTH hastalıklarıyla ilgili bir çalışma yapılmamıştır. Bu gen protein tirozin kinaz onkogen ailesinin bir üyesidir ve hücre büyümesinin kontrolünde yer alan, zarla ilişkili bir tirozin kinazı kodlamaktadır (34). Gelecekte FYN'nin OTH'yla ilişkisini ortaya çıkaracak deneysel çalışmalar yapılabileceğini düşünmekteyiz.

miRNA'lar gelişimsel açıdan mesajcı RNA'ların protein üretmesini düzenleyici rol üstlendiğinden, terapötik açıdan önemli olduğu düşünülmektedir (35). Çalışmamızın üçüncü ve son bölümü olarak, CTLA4 genindeki miRNA'ları tespit ettik ve CTLA- 4 genine ait önemli olduğunu düşündüğümüz 31 adet miRNA tanımladik.

Günümüzde polimorfizm çalışmaları biyobelirteç olarak kullanıldığı için oldukça revaçtadır. Polimorfizm çalışmaları; hastalığa yakalanma riski, kişinin hastalığa karşı verdiği immün cevap ve ilaçlara karşı gözlenen yan etkiler hakkında bilgi vermektedir. Çalıșmamızda ikinci olarak in silico araçları kullanarak, CTLA4 genindeki polimorfizmleri tespit ettik, Tablo 1'de Exome Variant Server, SIFT, Polyphen2 veritabanlariyla klinik bağlantısı henüz araștırılmamış 34 SNP bulduk. Bunlardan 8 tanesi missense mutasyondu. Süpheli olarak tanımlanan missense mutasyonlardan rs201778935, 
$\underline{\text { rs138279736, }}, \underline{\text { rs369567630 }}$ ve rs376038796'nın muhtemelen hasar verici tek nükleotid polimorfizmi olduğu düşünülmektedir.

\section{SONUÇ}

Çalışmamızın sonucunda 31 miRNA'nın mesajcı RNA’ların protein üretmesini düzenleyici rol üstlendiği ortaya konulmuş olup bu bulgunun terapötik açıdan önemli olduğunu düşünmekteyiz. Bulduğumuz tek nükleotid polimorfizmleri hakkında literatürde henüz bir çalışma bulunmamaktadır. İlerde bu polimorfizmlerin OTH ile ilişkisi deneysel olarak kanıtlanmaya muhtaçtır. Biyoinformatik yöntemlere dayandırılarak yapılan bu araştırmamızın ilerde laboratuvar ortamında uygulanacak birçok moleküler çalışmaya öncü olacağını öngörmekteyiz.

\section{ETİK BEYANLAR}

Etik Kurul Onayı: Bu çalışmada in silico metotlar kullanılmıştır ve herhangi bir etik kurul onayı gerektirmemektedir.

Aydınlatılmış Onam: in silico analiz olduğu için aydınlatılmış onamı gerektirmemektedir.

Hakem Değerlendirme Süreci: Harici çift-kör hakem değerlendirmesi.

Çıkar Çatışması Durumu: Yazarlar bu çalışmada herhangi bir çıkara dayalı ilişki olmadığını beyan etmişlerdir.

Finansal Destek: Yazarlar bu çalışmada finansal destek almadıklarını beyan etmişlerdir.

Yazar Katkıları: Yazarların tümü; makalenin tasarımına, yürütülmesine, analizine katıldığını ve son sürümünü onayladıklarını beyan etmişlerdir.

\section{KAYNAKLAR}

1. Brunet JF, Denizot F, Luciani MF, et al. A new member of the immunoglobulin superfamily CTLA-4. Nature 1987; 328: 267-70.

2. He F, Zhou Y, Wang X, et al. Functional Polymorphisms of CTLA4 associated with aggressive periodontitis in the Chinese Han population. Cell Physiol Biochem 2018; 50: 1178-85.

3. Li L, Liu J, Qin S, Li R. Correlation between CTLA-4 genetic polymorphisms, its serum protein level and the susceptibility to recurrent spontaneous abortion: A case-control study. Medicine (Baltimore) 2018 ; 97: e12754.

4. Yao L, Liu B, Jiang L, Zhou L, Liu X. Association of cytotoxic T-lymphocyte antigen 4 gene with immune thrombocytopenia in Chinese Han children. Hematology 2019; 24: 123-8.

5. Pistillo MP, Fontana V, Morabito A, et al. Soluble CTLA-4 as a favorable predictive biomarker in metastatic melanoma patients treated with ipilimumab: an Italian melanoma inter group study. Cancer Immunol Immunother 2019; 68: 97-07.

6. Fife BT, Bluestone JA. Control of peripheral T-cell tolerance and autoimmunity via the CTLA- 4 and PD-1 pathways. Immunol Rev 2008; 224: 166-82.
7. Melero I, Hervas-Stubbs S, Glennie M, Pardoll DM, Chen L. Immunostimulatory monoclonal antibodies for cancer therapy. Nat Rev Cancer 2007; 7: 95-06.

8. Linsley PS, Bradshaw J, Greene J, Peach R, Bennett KL, Mittler RS. Intracellular trafficking of CTLA-4 and focal localization towards sites of TCR engagement. Immunity 1996; 4: 535-43.

9. Esensten HJ, Helou AY, Chopra G, Weiss A, Bluestone AJ. CD28 costimulation: from mechanism to therapy. Immunity 2016; 17 : 973-88.

10. Kristiansen OP, Larsen ZM. CTLA-4 in autoimmune diseases--a general susceptibility gene to autoimmunity. Genes Immun 2000; 1: $170-84$.

11. Douroudis K, Prans E, Uibo R. CTLA-4 promoter polymorphisms are associated with latent autoimmune diabetes in adults. Hum Immunol 2009; 70: 921-4.

12. Hunt KA. A common CTLA-4 haplotype associated with coeliac disease. Eur J Hum Genet 2005; 13: 440-4.

13. Shojaa M. Association between 318C/T polymorphism of the CTLA-4 gene and systemic lupus erythematosus in Iranian patients. Int J Rheum Dis 2017; 20: 2040-4.

14. Online Mendelian Inheritance in Man. https://omim.org/. (Erişim Tarihi: 09.04.2020)

15. National Center for Biotechnology Information. https://www. ncbi.nlm.nih.gov/. (Erişim Tarihi: 09.04.2020)

16. NCBI-SNP. https://www.ncbi.nlm.nih.gov/snp/. (Erişim Tarihi: 09.04.2020)

17. Franz M, Rodriguez H, Lopes C, et al. GeneMANIA update 2018. Nucleic Acids Res 2018; 46: 60-4.

18. Mering VC, Huynen M, Jaeggi D, Schmidt S, Bork P, Snel B. STRING: a database of predicted functional associations between proteins. Nucleic Acids Res 2003; 31: 258-61.

19. Mutarelli M, Marwah V, Rispoli R, et al. A community-based resource for automatic exome variant-calling and annotation in Mendelian disorders. BMC Genomics 2014; 15: S5.

20. Sim LN, Kumar P, Hu J, Henikoff S, Schneider G, Pauline C. SIFT web server: predicting effects of amino acid substitutions on proteins. Nucleic Acids Res 2012: 40: 452-7.

21. Adzhubei I, Jordan DM, Sunyaev SR. Predicting functional effect of human missense mutations using PolyPhen-2. Curr Protoc Hum Genet 2013; 76: 7-20.

22. Wong N, Wang X. miRDB: an online resource for microRNA target prediction and functional annotations. Nucleic Acids Res 2015; $28:$ 146-52.

23. Dweep H, Sticht C, Pandey P, Gretz N. miRWalk database: prediction of possible miRNA binding sites by "walking" the genes of three genomes. J Biomed Inform 2011; 44: 839-47.

24. Brunner MC, Chambers CA, Chan FK, Hanke J, Winoto A, Allison JP. CTLA-4-Mediated inhibition of early events of T cell proliferation. J Immunol 1999; 162: 5813-20.

25. Buchbinder EI, Desai A. CTLA-4 and PD-1 Pathways similarities, differences, and implications of their inhibition. Am J Clin Oncol 2016; 39: 98-106.

26. Piccirillo CA, Shevach EM. Naturally-occurring CD4 + CD25 + immunoregulatory $\mathrm{T}$ cells: central players in the arena of peripheral tolerance. Semin Immunol 2004; 16: 81-8.

27. Takahashi T, Tagami T, Yamazaki S, et al. Immunologic selftolerance maintained by $\mathrm{CD} 25(+) \mathrm{CD} 4(+)$ regulatory $\mathrm{T}$ cells constitutively expressing cytotoxic $\mathrm{T}$ lymphocyte-associated antigen 4. J Exp Med 2000; 192: 303-9.

28. Chen K, Kolls JK. Interluekin-17A. Gene 2017; 30: 8-4.

29. Kim CH. FOXP3 and its role in the immune system. Adv Exp Med Biol 2009; 665: 17-9. 
30. Ganesh BB, Bhattacharya A, Gopisetty A, Prabhakar BS. Role of cytokines in the pathogenesis and suppression of thyroid autoimmunity. J Interferon Cytokine Res 2011; 31: 721-31.

31. Hu Y, Zhang L, Chen $\mathrm{H}$, et al. Analysis of regulatory $\mathrm{T}$ cell subsets and their expression of helios and PD-1 in patients with hashimoto thyroiditis. Int J Endocrinol 2019; 2019: 5368473.

32. Watanabe $\mathrm{A}$, Inoue $\mathrm{N}$, Watanabe $\mathrm{M}$, et al. Increases of CD80 and CD86 Expression on peripheral blood cells and their gene polymorphisms in autoimmune thyroid disease. Immunol Invest 2020; 49: 191-203.

33. Caio RDC, Quaio Jozélio F, Carvalho Clovis A, Bueno CS Amanda S. Autoimmune disease and multiple autoantibodies in 42 patients with RA Sopathies. Am J Med Genet A 2012; 158A: 1077-82.

34. Li J, Zhou H. Fyn gene polymorphisms contribute to both trait and state anxieties in healthy Chinese-Han individuals. Psychiatr Genet 2012; 22: 312-3.

35. Christopher AF, Kaur RP, Kaur G, Kaur A, Gupta V, Bansal P. MicroRNA therapeutics: Discovering novel targets and developing specific therapy. Perspect Clin Res 2016; 7: 68-74. 